\title{
SEMPERE GUARINOS ENTRE LA ILUSTRACION Y EL LIBERALISMO
}

\author{
Por Juan RICO GIMENEZ
}

Universidad de Alicante

\section{JUSTIFICACIONES}

La intención principal de este trabajo no es otra que la de añadir un matiz, una modulación o un color más a ese fascinante caleidoscopio que es nuestro siglo XVIII, quizás más sesudamente estudiado que afectuosamente imaginado. La figura notable de don JUAN SEMPERE GUARINOS, ilustrado de pro y liberal a su real gana, será esa modulación. Sobre la importancia y oportunidad de prestar atención a la figura considerada por muchos como poco relevante dentro del panorama de nuestra Ilustración, nosotros, obviamente, no necesitamos convencernos ya que, como historiadores de las ideologias, sostenemos la esencial pertinencia para el análisis de todos los modos o manifestaciones de la vida humana, individual o colectivamente considerada, y ello tanto en su dimensión teórica, reflexiva o mítica, como en su correlato activo, práctico o laborante (1). Pero es que, a más de la discutible respetabilidad epistemológica de tal postura, sucede que Sempere Guarinos dejó tras de sí tal rastro de opiniones y actitudes en torno a los temas considerados capitales en la España de su época.

(1) Châtelet. François: «Historia de las ideologías», I, Madrid, 1978, págs. 12-15. 
que le hacen acreedor, tanto al menos como a cualquier otro «preclaro» ilustrado, a no seguir manteniéndole durante más tiempo en el ostracismo y el olvido. Si la historia tiene que ser una historia «total», la posible aportación de Sempere a la historia de España ha de ser considerada. Por si hiciera falta alguna justificación más, ahí van las palabras de alguien con mayor autoridad que la de uno:

«Se hecha especialmente de menos un buen diccionario biográfico de
España, realizado a base de investigaciones sistemáticas en fuentes de
primera mano... Nuestro conocimiento sobre la biografía de los espa-
noles, incluso de aquellos de gran importancia histórica, es terrible-
mente limitado. Pero aún es mayor el desconocimiento casi absoluto
en que hay que moverse en personajes de segunda fila, pero de gran
importancia en la vida del país y en el desarrollo del Estado, como son
la mayoría de los consejeros y la alta burocracia». (2).

Ciertamente, Sempere Guarinos, por su condición y los puestos que ocupó pertenecería, al menos, a esta segunda categoría de pleno derecho.

Trataremos de dar medida de la importancia de Sempere, por un lado, a través del interés que su obra o su figura han suscitado en los estudiosos de su tiempo y de tiempos posteriores, nacionales y extranjeros. Por supuesto, no estarán todos los autores, que son muchos, sino sólo un muestrario que consideramos representativo, dadas las limitaciones de espacio. En algunas ocasiones, $y$ ai hilo de la referencia, analizaremos brevemente las perspectivas desde las que son valoradas determinadas actitudes de Sempere, con el fin de apuntar una serie de problemas en torno a su figura que esperamos plantear en toda la profundidad posible a lo largo de la tesis doctoral que sobre él estamos realizando. Por otro, haremos un bosquejo de la trayectoria ideológica del iluscrado alicantino tomando como datos su vida y su producción literaria.

\section{SEMPERE EN LA BIBLIOGRAFIA}

¿Cómo es que Sempere Guarinos, teniendo en cuenta la amplia atención historiográfica que ha despertado el siglo XVIII, no ha sido objeto aún de un trabajo monográfico extenso? Esta es una cuestión que le acucia a uno tanto más cuanta más literatura sobre el siglo ilustrado español lee. Rara es la publicación, nacional o extranjera, que no mencione al ilustrado eldense, en ocasiones, con mucha frecuencia, incluso en trabajos cuyo objeto desborda el tema ilustrado. Así, ocurre con la monumental y prestigiosa «Historia del análisis económico» de Joseph A. Schumpeter, y la no menos importante «Historia de la literatura española». de Nigel

(2) Elliot, John, De la Peñā, J.F.: «Memoriales y cartas del conde-duque de Olivares», I, Madrid, 1978, pág. XXIII. 
Glendining (3), pasando por los trabajos especializados de Sarrailh y Herr, de Elorza, Domínguez Ortiz y Maravall, de Mestre y Gil Olcina, o las estupendas tesis de estado de Demerson y François López (4), hasta estudios sociológicos como los de Werner Sombart (5), etc. No hay más que echar una ojeada a los índices onomásticos de tales obras para descubrir el nombre de nuestro ilustrado, en algunas ocasiones citado casi con tanta frecuencia corno los de un Jovellanos, un Campomanes o un Cabarrús, aunque, como tendremos ocasión de ver, la frecuencia de citas no esté en relación directa con el interés de los autores por la figura misma de Sempere.

Hasta ahora sólo hemos mencionado trabajos relativamente reciertes (6). No falta, desde luego, Sempere, en la consideración del buscaherejes Menéndez Pelayo, para quien aquél estaria, probablemente, entre los que actuaron de buena fe pero descarriados ideológicamente, regalistąs, enciclopedistas, es decir, entre los que el bueno de don Marcelino llamó «herejes administrativos» (7). Pero quizá aún tengamos ocasión de volver sobre nuestro polígrafo nacional.

En lo que se refiere a su propio tiempo y al inmediatamente posterior, Sempere es incluido en trabajos como el de Lesén Moreno (que lo conoció personalmente y lo admiró), los de La Sagra, Colmeiro, Becker, Mollá,

(3) la de Schumpeter publicada en Barcelona en 1971; la de Glendining también en Barcelona en 1974, corresponde al tomo IV, dedicado al sigio XVIII.

(4) - Sarrailh, Jean «La España ilustrada de la segunda mitad del siglo XVIII«, Madrid y México, 1974.

- Herr, Richard: «España y la revolución del s. XVIII«, Madrid, 1975.

-Elorza, Antonio: «La ideología liberal de la llustración española», Madrid, 1970.

--Dominguez Ortiz, Antonio: Sociedad y Estado en el XVIII español», Barcelona, 1976.

--Del prof. Maravall (José Antonio) oímos por primera vez el nombre de Sempere Guarinos, en sus explicaciones de cátedra en la Facultad de Ciencias Políticas de Madrid.

-Mestre, Antonio: «Humanismo y crítica histórica en los ilustrados alicantinos». Lección inaugural del curso académico 1980-81. Universidad de Alicante, 1980. El prof. Mestre, actual Decano de la Facultad de Letras de Alicante y reponsbie en ella del Departamento de Historia moderna, fue quien nos propuso el trabajo sobre Sempere como materia de tesis doctoral.

-Gil Olcina, Antonio: «La propiedad señorial en tierras valencianas», Valencia, 1980.

—Demerson, George: «Don Juan Meléndez Valdés y su tiempo», 2 vols. Madrid, 1971.

-López, François: «Juan Pablo Forner et la crise de la conscience espagnole au XVIIle siecle», Bordeaux, 1976.

(5) Sombart, Werner: «El burgués». Madrid, 1977.

(6) Parece ser que un profesor de Literatura de la universidad de Bolonia (Italia) se está interesando también por Sempere.

(7) Menéndez Pelayo, Marcelino: «H. ${ }^{\text {a }}$ de los heterodooxos españoles», II, Madrid, 1956. 
Milego y Galdo, Rico y Montero, etc. (8).

Pero, la pregunta arriba planteada tiene, no obstante, alguna respuesta satisfactoria. Primera, que no es totalmente cierto que nuestro autor no haya sido estudiado con cierto detenimiento. En efecro, Ramón Carande y Rodrigo Fernández Carvajal se han ocupado de Sempere en sendos trabajos que analizaremos más tarde. La segunda, a su vez, explica esa ausencia de trabajos monográficos puesto que, salvo excepciones, como veremos, la mayoría de citas y alusiones se refieren a Sempere y sus actitudes sólo indirectamente ( $\mathrm{y}$ a veces ni eso), centrándose, en cambio, en la utilidad de su obra para analizar aspectos de nuestra ilustración. Puede decirse, pues, que, en general, Sempere no interesa demasiado en sí mismo, al menos en el sentido del interés que despiertan otras figuras de su tiempo, Jovellanos a la cabeza. Situación que contrasta con la manifiesta en su propia época, donde Sempere era considerado, tanto por sus compatriotas como por foráneos, figura importante de la élite ilustrada española. Considérense algunos datos:

- premios otorgados por la Sociedad Económica de Madrid y la Academia de Santa Bárbara respectivamente (9), el primero por la «Memoria sobre la prudencia en el repartimiento de la limosna», que Sempere presentó al concurso convocado por aquella en 1781, y el segundo por la disertación sobre la «Policía de las diversiones populares», leída en la propia Academia en 1784 ;

- relaciones personales con otros ilustrados «ilustres», como Jovellanos y Floridablanca, el abate Andrés, Campomanes, Pérez Bayer, Casafonda, Mayans, Meléndez Valdés, etc. (10).

- eco nacional y foráneo de su obra (traducciones, comentarios, correspondencia...). Del «gran número de cartas escritas...; artículos y citas muy honoríficas de varios periódicos y de otros autores nacionales y extranjeros» (11), Sempere selecciona los que le parecen más representativos, como los comentarios del viajero Bourgoing o los artículos aparecidos en

(8) -Lesen Moreno, José: «H." de la Sociedad Económica de Amigos del País de Madrid», Madrid, 1863.

- La Sagra, Ramón: «Catálogo de escritores económicos españoles», Madrid, 1848.

-Colmeiro, Manuel: «Bibilioteca de los economistas españoles de los siglos XVI, XVII, y XVIII", Madrid, 1890.

-Bécker, Jerónimo: «La tradición política española. Apuntes para una biblioteca española de políticos y tratadistas de filosofía política», Madrid, 1896.

-Mollá, Milego y Galdo: «Ensayo bio-biliográfico de escritores de Alicante y su provincia», Alicante, 1888.

(9) «Noticias literarias de Sempere», Madrid, 1821, págs. 2-3

(10) Ibídem, págs. 4, 5, 23-32. Vid. También López, op. cit., pág. 177

(11) Ibidem, págs. 3, 23 y ss. 
Florencia y Roma a propósito de la aparición del «Ensayo de una biblioteca de los mejores escritores del reinado de Carlos III» (que en adelante reconoceremos como «Ensayo»).

\section{PRESUPUESTOS EPISTEMOLOGICOS Y METODOLOGICOS DEL OBJETO HISTORIOGRAFICO}

Resulta significativo, en relación a la falta de interés por Sempere en la historiografía actual, el hecho de que sea precisamente, y en una proporción muy considerable, su obra menos creativa y personal la más citada. Ciertamente, los seis tomos del «Ensayo», publicados entre 1785 y 1789 , es decir, cuando el autor apenas sobrepasaba la treintena, escrito con intenciones apologético-nacinalistas y probablemente interesadas por su parte, que conocía los medios de encumbramiento social derivados del prestigio literario, representan una obra notable pero también criticable. Notable puesto que el «Ensayo», supone una comodísima fuentẹ de primera mano para el estudio de la producción intelectual ilustrada española. De ello da medida, aparte la mencionada frecuencia con que esta obra es consultada, el hecho de que, a excepción de la «Historia del lujo y de las leyes suntuarias de España» (obra más personal que comentaremos aparte), haya sido la única reeditada recientemente (12). Criticable porque, como también se ha detenido a ver F. López, existen en ella algunas parciạlidades que quizá no tenían por qué, o sí lo tenían, si valoramos el asunto desde la intención de Sempere al escribir la obra. Pero de esto hablaremos en su momento. Lo que nos interesa resaltar aquí es que de la limitada preocupación historiográfica por el ilustrado alicantino, unida a una cierta tendencia a usar tópicos, la imagen resultante nos parece esquemática, estereotipada y excesivamente «impresionista». Así la mayoría de los autores resumen a Sempere con dos adjetivo: realista y afrancesado. Nosotros también creemos que lo fue, pero sostenemos que también fue algo más que eso y nuestra labor estriba, consiguientemente, en intentar superar tales apreciaciones apresuradas delineando un retrato lo más completo posible de nuestro modelo. Que lo consigamos o no, ese será otro negocio, del que únicamente nosotros pagaremos la factura. El asunto no es precísamente fácil, ya que Sempere parece, a veces, el hombre de las mil caras y uno no sabe muy bien con cual de ellas quedarse, pero, ¿açaso esa incoherencia de actitudes vitales y políticas no se deja ver en todos los españoles contemporáneos suyos que como él tomaron partido por la modernización y el progreso del país? Así lo cree-

(12) Sempere Guarinos, Juan: «Ensayo de una biblioteca de los mejores escritores del reinado de Carlos III», edición facsímil en Gredos, Madrid, 1969, 3 vols. Vid. el discurso preliminar incluido en el vol. I, págs. 1-50. Vid. también López, op. cit., pág. 63. 
mos, y por eso pensamos que aciarar la postura y las contradicciones de Sempere a lo largo de su, a la vez tranquila y ajetreada vida, puede servir para dar un poco más de luz a esa controvertida época que se despliega desde el reinado de Carlos III hasta la segunda reacción absolutista fernandina.

Para esta tarea, el terreno ya está parcialmente allanado. No hay más que ojear la historiografía más avalada sobre el siglo XVIII (nacional, pero también extranjero), para contactar con una valoración común del mismo (máxime cuando se trata de analizar actitudes, mentalidades o ideologías): la contradicción. Por ejemplo, «el carácter esencialmente contradictorio de la ideología ilustrada», constituirá el objetivo de un trabajo monográfico (13), así como uno de los elementos que resaltan en otros análisis no menos importantes (14), uno de los cuales adopta precisamente el significativo título de «Continuidad y contradicción en la Ilustración española» (15)

¿Continuidad y contradicción como opuestos e irreconciliables? Aquí topamos con un problema semántico o, mejor dicho, semiológico que es, cuando menos, peliagudo, si no puramente ideológico. Porque, ¿qué queremos decir con eso de que el pensamiento ilustrado fue esencialmente contradictorio? (16) ¿Fué o es? ¿Quiére decir que nuestros ilustrados pensaban y sentían «contradictoriamente» la falta de correspondencia entre su ideología moderna como superestructura mental y su soporte, una estructura económica también moderna y burguesa? Ello supondría, creemos, una aplicación excesivamente cómoda de las metodologías marxista y estructuralista y, en definitiva, una manipulación y un defecto (interesado o inconsciente) en la comprensión cabal de ciertos fenómenos. Es cierto que la historia se escribe desde el presente, pero ello no justifica que olvidemos que cada época y cada lugar tienen un zócalo de sedimentación de sentido de la realidad que es, en última instancia, el que condiciona las peculiares perspectivas y actitudes que se conjugan en torno a ellas. Si aceptamos tal relativismo epistemológico, puede colegirse que tal vez el pensamiento ilustrado fuera más contradictorio para nosotros sus estudiosos que para sus

(13) Elorza, op. cit., pág. 14

(14) -Mestre, Antonio: «Despotismo e Ilustración en España», Barcelona, 1976 -Maravall, José Antonio: «Las tendencias de reforma política en el siglo XVIYI», Rev. de Occidente $n .^{\circ}$ 52, 1967, págs. 53-82.

-Tierno Galván, Enrique: prólogo a las «Reflexciones sobre la revolución francesa», de Burke. Madrid, 1978, págs. 7-21.

-Aranguren, José Luis: «Moral y Sociedad», Madrid, 1977, págs. 15-22.

(15) Sánchez Agesta, Luis: "Continuidad y contradicción en la Ilustración española», Rev. Estudios Políticos n. ${ }^{\circ} 192,1973$, págs. 9-24

(16) Sobre el proceso del concepto de contradicción. vid. Ferrater Mora, «Diccionario de Filosofía", vol. I, Madrid, 1979, págs. 622-624 
productores mismos o que, por lo menos, las contradicciones sentidas por ellos y las imaginadas por nosotros hablando de ellos, serían de naturaleza diferente. Ya que parece fuera de toda duda que los ilustrados todos, españoles y no españoles, al desarrollar sus ideas en una época tremendamente crítica, de transición y ruptura pero de variadas modalidades, no podían formar ( $y$ mucho menos tener conciencia de) una estructura común y compacta de pensamiento, es decir, de clase. De ahí la dificultad de toda historiografía reduccionista y globalizante cuando trata épocas esencialmente conflictivas y «contradictorias». Así lo reconoce, por ejemplo, Antonio Elorza en su intento de generalizar sobre la ideología liberal de nuestra ilustración (17), intento sumamente logrado, por otra parte.

Pero, ¿cómo puede evitar el historiador la generalización o, como dice Foucault, la necesidad de

«encontrar, a un nivel más o menos profundo, un principio de cohesión que organiza el discurso y le restituye una unidad oculta»?

Será, como sigue diciendo el célebre investigador francés, porque

«esta ley de coherencia es una regla heurística, una obligación de procedimiento, casi una compulsión moral de la investigación: No multiplicar inútilmente las contradicciones; no caer en la trampa de las pequeñas diferencias, no conceder demasiada importancia a los cambios, a los arrepentimientos, a los exámenes de conciencia, a las polémicas; no suponer que el-discurso de los hombres se halla perpetuamente minado en su interior por la contradicción de sus deseos, de las influencias que han experimentado o las condiciones en que viven; sino admitir que si hablan, y si entre ellos dialogan, es mucho más por superar esas contradicciones y encontrar el punto a partir del cual pueden ser dominadas. Pero esa misma coherencia es también el resultado de la investigación: define las unidades terminales que consuman el análisis; descubre la organización interna de un texto, la forma de desarrollo de una obra individual o el lugar de encuentro entre discursos diferentes. Se está obligado a suponerla para restituirla, no se estará seguro de haberla encontrado más que en el caso de que se la haya perseguido hasta muy lejos y durante largo tiempo. Aparece como un óptimum: el mayor número posible de contradicciones resueltas por los medios más sencillos» (18).

Perdóneseme la larga cita de Foucault, pero sus observaciones me parecen muy sugestivas, no sólo al nivel de la crítica del conocimiento histórico, siempre de agradecer, sino por lo que puedan servir de aclaratorias y hasta paradigmáticas para el estudio de nuestro Sempere Guarinos, hombre, según todos los indicios, especialmente «contradictorio».

(17) Elorza, op. cit., págs 14 ss.

(18) Foucault, Michel: «La arqueología del saber», México, 1978, págs. 250-251. 
Ahora bien, el problema no acaba aquí, porque; ¿qué medios emplearemos para resolver la aparición de contradicciones? ¿Negarlas, definiendo un campo de no-contradicción y sometiendo a él toda variante? Esa es la línea de todo sistema lógico, que a nosotros no nos parece la más correcta, aunque su discurso sea de los más impecables en presentación y forma. En realidad nos interesa más el fondo que la forma, o sea, el hombre profundo, tanto en su grandeza como en su mediocridad. Por eso preferimos adoptar un método policéfalo, lógico y analógico, sincrónico y diacrónico, y aplicarlo a Sempere como individuo que fue, mas sin olvidar de insertarlo en las dimensiones colectivas y generales de conciencia de su época. Así, si en las actitudes del ilustrado sospechamos algún tipo de coherencia manifiesta por debajo de sus contradicciones, tal coherencia no podría explicarse mejor que desde el ente peculiar y diferenciado que fue el mismo Sempere. $\mathrm{Si}$, en cambio, contemplamos tales contradicciones desde la órbita colectiva y general diacrónica, probablemente resaltarán más que su posibie coherencia. Nos movemos siempre, pues, por terreno tanto más resbaladizo cuanta mayor porción de verdad queremos apresar. Pero retomemos el hilo inicialmente enhebrado.

\section{SEMPERE, OBJETO DE ESTUDIO}

Del año 1955 datan precisamente dos trabajos sobre Sempere, aunque no tengan filiación común alguna.

A) El de don Ramón Carande (19), se basa en la colección de las obras de Sempere (dieciséis tomos en folio, encuadernados en pasta española) que conserva la Real Academia de la Historia, colección que, según Carande, «reúne materiales dignos de estudio, lamentablemente preteridos». El estudio, más que exhaustivo y crítico, es más bien didáctico, y el prof. Carande, con muy buen criterio pedagógico, se limita a llamar la atención sobre la importancia que la colección contiene para la comprensión cabal de la política del despotismo ilustrado español y de la seguida en decenios posteriores a la revolución francesa. Para ello presenta los materiales de Sempere en una ordenación sistemática que resulta verdaderamente útil para el investigador. Por lo demás, Carande escribe una rápida semblanza biobibliográfica que, siendo correcta en líneas generales, adolece de ciertos errores de precisión que no hay que atribuir al gran historiador de las finanzas imperiales sino, simplemente, a la falta de datos más fidedignos. Y aquí hay que complicar al propio Sempere como primer responsable de esas lagunas en torno a bastantes asuntos relacionados con su vida. Ffecti-

(19) Carande y Thovar, Ramón: «Catálogo de la colección de manuscritos e impresos de ciencias económicas y jurídicas de don Juan Sempere y Guarinos». Real Academia de la Historia, Madrid, 1955. 
vamente, si hemos de considerar las «Noticias literarias de Sempere» como fuente autobiográfica principal, al terminar de leer esas parcas sesenta y ocho páginas, escritas además en tercera persona, desprovistas de toda consideración personal que no sea desde la esfera del hombre público, no podemos evitar la desazón propia del curioso que quiere ir más allá (o más acá) de la mera declaración formal. Después de todo, la autobiografía, junto con la correspondencia privada y el diario, son las fuentes más fieles para el análisis de una personalidad, para una buena biografía, en suma. Fuentes que, en el caso de Sempere Guarinos, son desgraciadamente demasiado escasas hasta el momento. Esperamos, en el apartado de la correspondencia, hallar más pistas, aunque tenemos fundamento para sospechar que gran parte de ella (que parece fue considerable) sea ya irrecuperable, un poco por negligencia del propio Sempere y sus herederos, quizá un mucho por rapiña de coleccionista insolidario, especie bastante extendida entre nosotros. En fin, todas las reseñas biográficas de nuestro autor se basan en la citada «Noticias» y, en pocos casos, en algo más, como ocurre en la obra de Rico y Montero, que tuvo en cuenta los datos que recogió don Lamberto Amat en su todavía inédita (desde hace casi un siglo) «Historia de Elda» (20). Por nuestra parte, hemos aclarado ya algunos de los datos dudosos o falsos que recogen Carande y otros, fundamentalmente a través de investigaciones realizadas en Orihuela, Madrid, Granada e, incluso, leyendo las obras de Sempere posteriores a la edición de las «Noticias» (1821). Por ejemplo, de los documentos hallados en el Archivo Histórico de Orihuela (en proceso de catalogación, pero riquísimo en información, como demostrarán en su día los compañeros Mario Martínez y David Bernabé, entre otros), se desprende que Sempere no estudió Leyes (Derecho) en Valencia, como afirma Carande, sino en la propia Universidad oriolana y en el Colegio de San Isidoro de Murcia, y que en Valencia, como el propio Sempere indica, únicamente «pasó dos años la práctica de abogado» (21), que fueron los de 1778-79, después de realizar práctica docente como catedrático de filosofía en el mismo seminario de San Miguel de Orihuela donde iniciara sus estudios (vid. documento anexo).

Pero éste es un detalle sin demasiada importancia. Mayor la tiene la duda sobre si Sempere rompió su exilio francés durante el llamado «Trienio constitucional» de 1820-23. En este caso comparto la sospecha de don Alberto Navarro Pastor (corresponsal del prof. Carande para el trabajo de éste) en el sentido de que, en efecto, nuestro ilustrado regresó a España durante el corto impasse liberal para volver de nuevo al exilio ante la repetida amenaza reaccionaria de 1823 , esto probablemente desde Cádiz. Además.

(20) Hemos podido acceder a ella gracias a la generosa ayuda de nuestro amigo José R. Valero, de Elda, que la ha grabado en cinta para nosotros en casa de los herederos del Sr. Amat.

(21) «Noticias literarias..», cit. pág. 1 
y contrariamente a lo afirmado por los biógrafos citados (22), durante este interregno de libertad pudo Sempere recuperar todo su patrimonio confiscado, ya que no los cargos públicos que anteriormente ejerciera. Así lo afirma el propio repatriado en el prólogo al tomo I de su «Historia del Derecho español»:

«Desterrado, despojado de mis bienes y de mis honores por el gobierno absoluto, a la Constitución debo el dulce consuelo de respirar otra vez los aires puros de mi amada patria; la devolución de mis bienes; el más estimable de los inapreciables derechos de ciudadano español; la satisfacción de que las Cortes hayan admitido con agrado dos obritas que les he presentado; que el gobierno me haya otorgado cuanto le he pedido; y que las personas más ilustradas de todos los partidos, en que desgraciadamente está dividida esta península, no desconozcan mis antiguos méritos» (23).

Por otra parte, tampoco parece cierta la apreciación del momento del primer exilio de Sempere, que yo también situaba en la definitiva salida de José Bonaparte, sus huestes y la mayoría de los afrancesados, llevada a cabo entre la primavera y las proximidades del verano de 1813, a través de Vitoria y San Juan de Luz (24). La aclaración, que resulta muy significativa respecto a la actitud y relaciones de Sempere con el liberalismo constitucional, nos la ha proporcionado casualmente nuestro compañero Glicerio Sánchez Recio al descubrir, en sus investigaciones sobre la estructura electoral de Elda, a un tal Juan Sempere Guarinos, fiscal, como miembro de la Junta Electoral de Elda, constituida por elección censitaria en marzo de 1814 (25). Ese nombre y esa profesión, en el pequeño pueblo de Elda de entonces, no pueden corresponder más que a la misma persona, esto es, a nuestro ilustrado, fiscal en la Chancillería de Granada y en el Consejo Supremo bonapartista. ¿Qué pasó en la mente de Sempere en esos momentos graves en que sabía, si triunfaba la reacción (había tenido ya pruebas en su reciente encarcelamiento madrileño, por colaboracionista), que se jugaba el porvenir y quizá el tipo? Si quería evitar el desagradable exilio, pasándose a la clandestinidad simulando una falsa huída a Francia, desde luego su patria chica era un buen refugio. Pero malamente iba a poder camuflarse dando la cara y, mucho menos, formando parte de la junta electoral constitucional. ¿Entonces? Simplemente algo tan obvio, aunque sorprendente, como que el recalcitrante ilustrado (que por otra parte ya tenía la edad po-

(22) Rico y Montero, op. cit., pág. 248

(23) Sempere y Guarinos, Juan: «H.” del Derecho espaíol», 2 vols., I, 1822; II, 1823, Madrid, Imp. Nacional.

(24) Mercader Riba, Juan:«José Bonaparte, rey de España, 1808-1813», Madrid, 1971, págs. 368-371.

(25) Sánchez Recio, Glicerio: «Elda en 1812. Las elecciones del primer ayuntamiento constitucional». Rev. Alborada n. ${ }^{\circ}$ 26, Elda, 1980. 
co pueril de sesenta años), había tomado partido, como tantos otros, por la causa constitucional, con la esperanza de que fuera sancionada por el Rey Deseado tras su inminente llegada de Francia. Y ello a pesar de sus diferencias claras y expresas con los constitucionalistas de Cádiz, aunque todo hace pensar que se trataba de diferencias de procedimiento más que ideológicas, como seguiremos teniendo ocasión de ver. En el fondo, la Constitución sancionada por la Monarquía o, como la llamamos después, la monarquía constitucional era, para Sempere como para los liberales, la continuación lógica del despotismo ilustrado de Carlos III, truncado por el caprichoso y estéril de Carlos IV y Godoy, la revolución francesa y la reacción interior consiguiente $\mathrm{y}$, finalmente, por la invasión napoleónica. Por todo ello se refugió Sempere en su pueblo y allí participó en la alternativa constitucional, pensando que ésta sería la respuesta política predominante tras la vuelta de Fernando VII. Dado que la respuesta fue precisamente la contraria, la de la reacción y el ultramontanismo inquisitorial, y Sempere sabía que allí no tenía cabida alguna, optó entonces por el exilio. Lo que sigue sorprendiéndonos, en éste como en otros aspectos, es el desinterés casi absoluto del ilustrado por precisar estos acontecimientos, tan preciosos para el historiador en general y el de las ideologías en particular (26).

Resumiendo, el trabajo de Carande es doblemente meritorio. Por un lado, por lo que en su catalogación facilita la labor investigadora posterior, algo que le tendremos que agradecer en toda su extensión cuando hayamos concluido nuestra tesis; por otro, por las sugerencias críticas que apunta en su reseña biográfica, todas ellas muy aprovechables, especialmente las relaciones entre la posible influencia extranjera (afrancesamiento) y el liberalismo del ilustrado en materias como la economía y la política social (aunque Carande también acepte la fama más de antiguo régimen que de liberal de Sempere).

B) El estudio de Fernández Carvajal (27) es digno y serio, pero creemos que resuelve con demasiada prisa el problema de las contradicciones ideológicas de Sempere, aventurando valoraciones poco consistentes, por ejemplo, la que le lleva a comparar, en oportunismo político, al ilustrado con Fernando VII (28). ¡Pobre Sempere! Queremos pensar que en este análisis de la retórica al servicio del oportunismo político, Fdez. Carvajal había matizado sus conclusiones si hubiera sabido algunas cosas más sobre el ilustrado, como su actuación en Elda en 1814 o su estancia en España durante el Trienio liberal. Es muy probable que ignorara el primer dato. $\mathrm{Pe}$ -

(26) «Ensayo», cit., prlogo al vol. II, pág. VII.

(27) Fernández Carvajal, Rodrigo: «La historiografía constitucional de Sempere Guarinós», Rev. Est. Políticos n. ${ }^{\circ} 82$, Madrid, 1955, págs. 61-95.

(28) Ibídem, pág. 95. 
ro, ¿y el segundo? ¿Acaso no dedica buena parte de su artículo al análisis de la «Historia del Derecho español»? ¿No consideró dignas de ser tenidas en cuenta las afirmaciones de Sempere en los prólogos y al final del tomo II? Da ìa impresión de que Fdez. Carvajal no está en modo alguno dispuesto a dar credibilidad a las adhesiones expresas de Sempere al constitucionalismo liberal, y sí sólo a tenerlas en cuenta como retórica oportunista. En fin, pensamos que quizá si hubiera meditado más profundamente sobre la relación dialéctica entre ilustración y liberalismo constitucional, a nivel ideológico, no hubiera hallado tanta incoherencia. Por ejemplo, le invitamos a leer, por citar uno sólo, el exhaustivo trabajo de F. López sobre Forner, ya apuntado, como muestra de que, en el pensarniento ilustrado espanol, «no todo el monte es orégano», y que la mayoría de los ilustrados, como de los liberales decimononos, por no decir todos, fueron oportunistas en política y contradictorios en pensamiento y acción, lo cual no significa que no actuaran đe buena fe. Simplemente, la turbulencia de los acontecimientos les desboróó constantemente. Si Sempere destaca más que otros, ello se debe al hecho, «rara avis» en nuestro país, incluso ahora, de que ideológicamente era ilustrado, liberal y conservador, a la vez y siempre. El prototipo de tal ideología, como ha demostrado con meridiana claridad el prof. Tierno Galván (29), es Edmundo Burke, tan admirador de las revoluciones liberales inglesa y americara como reprobatorio de la francesa, aún aceptando en las tres las mismas filiaciones teóricas e ideológicas. Se trata, en Burke como en Sempere, de optar por la libertad y el progreso, pero sin rupturas drásticas, sin desdeñar el bagaje positivo que, según ellos, todo pasado inmediato contiene. «Los hombres pasan, los principios cambian, las instituciones siguen» (30), sería el eslogan ideológico de estos individuos recalcitrantes y pragmáticos, empeñados en unir tradición y modernismo con el auxilio de algunos instrumentos básicos, la razón, el sentido común y el estudio desapasionado de la historia (Sin embargo, hay que matizar que, en muchos aspectos, no es Burke, sino Montesquieu quien está más cerca de Sempere). En este sentido choca, como le ocurre a Carande (31), la imputación de «pesimismo temperamental» (32) ante la historia que Fdez. Carvajal atribuye a Sempere, atribución que sólo se explica tras la comparación de las tesis de Sempere y Martínez Marina sobre los presupuestos históricos de la Constitución de 1812 y la toma de partido a favor de este último. Más aún, Fdez. Carvajal, partiendo de tal asunción afirma que Sempere

«no tiene esa necesidad de buscar legitimaciones históricas positivas que apunta en Jovellanos y que aflora en Martínez Marina» (33).
(29) Tierno Galván, op. cit.
(30) Ibídem, pág. 13.
(31) Carande, op. cit., pág. 22.
(32) Fernández Carvajal, op. cit., págs. 70-71.
(33) Carande, Ramón: "Carlos $V$ y sus banqueros», vol. II, sección $4 .^{\text {a }}$, cap. XII, Madrid, 1949.


No es exactamente eso lo que ocurrió. Al contrario, Sempere buscó, todo lo que su energía y su entendimiento le permitieron, esas legitimaciones. Lo que ocurrió, simplemente, es que no las encontró. Y así lo expuso, lo que le valió el desdén y, en el mejor de los casos, la desconfianza de los seguidores de Marina, quien sí creyó encontrarlas y cuya tesis, además, fue la que tuvo éxito en los ambientes liberales. He aquí, de paso, la clave primordial de la falta de entendimiento entre Sempere y un sector de los liberaies, como del sambenito de antiliberal que aún le cuelga. Respecto a aquello, el problema, ahora como entonces, estriba en saber quién iba más encaminado, si Sempere o Martínez Marina. El propio Carande opta por el alicantino al situarse entre

«quienes buscan en vano sobre las actas de las Cortes de Castilla del s. XVI y en la actución de los procuradores (privilegiados, dóciles o serviles) el rastro de las libertades castellanas» (34).

En lo que sí creemos que lleva razón Fdez. Carvajal es en la afirmación de que Sempere no era un romántico, y no sólo eso, sino que, al modo como hacían Burke y Jovellanos con los revolucionarios franceses, desdeñaba a los románticos por apasionados y poco cuerdos en sus conductás políticas (35). En cualquier caso, tendríamos que matizar respecto al romanticismo, que no fue precisamente homogéneo ideológicamente, ni se puede confundir todo él con el liberalismo democrático.

Queda dicho, no obstante las discordancias apuntadas, que el trabajo del prof. Fernández Carvajal es importante, no sólo desde su perspectiva jurídico-política, sino como incitador a un estudio más profundo de la figura de Sempere Guarinos.

\section{VIDA Y OBRA}

Nació Juan Sempere Guarinos el 8 de abril de 1754 en Elda, pueblo de la provincia de Alicante que por aquel entonces contaba unos 3.000 habitantes, la mayoria dedicados a la agricultura y la industria transformadora del esparto, ocupándose los restantes en algunas fábricas de aguardiente, jabón, lienzo, papel y teja (36). Su familia disfrutaba, al parecer, de una posición económica relativamente desahogada y de buen ascendiente social, asentada en Elda desde la instalación de los castellanos reconquistadores, «cristianos viejos, limpios de toda mala raza y gente principal y noble», según consta en el expediente de hidalguía dei hermano mayor y primogénito de Juan, Manuel Sempere Guarinos, Primer Teniente de las Milicias Urbanas del reino de Valencia, presentado en 1795 (37).

(35) - «Noticias», cit., págs. 18-19

(36) Canavilles: «Observaciones sobre la historia natural, geografía, agricultura, población y frutos del reino de Valencia), vol. II, Madrid,1797, pág. 258

(37) Archivo de la Real Chancillería de Granada, sala 304, leg.525, pieza 4 
No disponemos de datos sobre la infancia de Juan Sempere en Elda, a falta del definitivo y problemático esfuerzo de indagación cerca de sus herederos más inmediatos. No cabe imaginar cosas extraordinarias habida cuenta del escenario tranquilo y reducido en el quē se desenvolvió aquella, salvo, quizá, el interés que despertara en los padres la conveniencia de dar estudios a un niño que indudablemente daba muestras de aplicación e inteligencia notables. Para tan encomiables proyectos, no tenían aquellos honrados «cristianos viejos» lugar más idóneo y relativamente cercano que Orihuela, entonces importante y «honorable» centro cultural del Levante español. El destino de aquel niño de apenas diez años estaba, pues, definitivamente resuelto. Algo semejante a lo que estaría ocurriendo a otros muchachos cuyos nombres también pasarían a la celebridad y con los cuales Juan Sempere tendría relaciones: Meléndez Valdés, Martínez Marina, Forner, por citar algunos.

Entretanto, por Europa galopaba el brioso corcel de la Razón, cautivador y pavoroso, levantando olas de entusiasmo en unos y atrincherando a otros. Los descubrimientos científicos y técnicos, el pensamiento de los Newton, Locke, Hume, Montesquieu, Voltaire, Rousseau, Quesnay, Adam Smith, Beccaria, Turgot, Condorcet y un largo etcétera, fundarían los nuevos altares del Occidente, que ya no se llamaría otra cosa que «la Civilización», es decir, «la Humanidad», que, según Kant, había alcanzado la mayoría de edad y, consiguientemente, tenía el derecho y el deber de propagar la buena nueva a todos los rincones del mundo, por fin cognoscible, aún a costa de inventar el imperialismo político. Todo lo anterior a la Edad de la Razón y de las Luces eran, obviamente, sombras, edades oscuras. Tal era la ideologia que se impuso poco a poco en España y que contribuyeron a reforzar los representantes de la nueva dinastía en el poder, de origen precisamente francés. La posterior noción ilustrada de la decadencia española del siglo XVII, en la que colaboró no poco el propio Sempere, tiene mucho que ver con esto.

1765. El caso es que, con poco más de diez años, nuestro Sempere ingresa en el Seminario de San Miguel y la Purísima Concepción de Orihuela, instaurado por el obispo Gómez de Terán en 1742, como colegial «porcionista» (régimen mixto, entre interno y externo, previsto para los estudiantes que no necesariamente pretendían la carrera sacerdotal). Acerca de la constitución, pedagogía y formación en los seminarios de la época, remitimos al documentado trabajo de Fco. Martín Hernández (38).

Por Orihuela no pasó Sempere como un colegial desapercibido. Antes bien, y durante todos los cursos que allí recibió, destacó por su aplicación y brillantez en los ceremoniosos y rigurosos exámenes, alcanzando los mayores premios, particularmente en los estudios de filosofía (vid. documento

(38) «La formación del clero en los siglos XVII y XVIII», en «H. ${ }^{a}$ de la Iglesia en España», dirigida por el prof. Mestre, vol. IV, Madrid, 1979, págs. 524-582 
anexo). Terminados sus estudios en el seminario, pasó a los de la universidad literaria (39), regentada por los dominicos, con igual aplicación. Finalmente, obtuvo una beca del obispo Tormo para continuarlos en el Colegio de San Isidoro de Murcia, establecido en 1733 por el cardenal Belluga como anexo al seminario de San Fulgencio y dotado con cátedras de derecho civil y canónico. El mismo obispo Tormo desea la vuelta de Sempere a Orihuela, para lo que le nombra catedrático de filosofía del Seminario, actividad que el joven eldense desarrolla durante dos cursos. Hemos encontrado en el Archivo de Orihuela una tesis de grado oue dirige Sempere, leída en junio de 1778 en la iglesia de Stas. Justa y Rufina por su defensor, José Olivas y Denia.

1778. Sempere se hallaba, pues, a sus veinticuatro años, con el porvenir resuelto si así lo quería. Pero, por lo visto, la perspectiva de convertirse en un grave y reputado personaje provinciano no le animó lo suficiente, ya que sus miras eran otras. Sin embargo, ¿porqué de Orihuela se trasladó a Valencia y no directamente a Madridd? ¿Quizá porque conocía el prestigio que en Valencia tenían los Mayans y su grupo, y la labor ilustradora de otras instituciones como la Sociedad Económica y la Junta de Comercio y Agricultura? Tal vez fuera así (40). Después de todo, como ha demostrado sobradamente el prof. Mestre Sanchís, entre otros, Gregorio Mayans era bien conocido en el mundo ilustrado (nacional y extranjero) de mitad del siglo como una de las cabezas pensantes de que más podía presumir la España progresista. Suponemos, además, que en la elección de Sempere intervinieron también razones sentimentales y prácticas: Valencia era la capital del reino y también tenía más fácil comunicación con Elda que Madrid. Lo que no sabemos aún es si la idea primera fue la de instalarse en Valencia, con qué proyectos y, finalmente, cuáles fueron las causas para decidir el nuevo traslado a Madrid. Parece bastante claro, al menos, que la primera intención de Sempere al abandonar Orihuela era la de dedicarse a la jurisprudencia, profesión que suponía un excelente medio para labrarse un porvenir brillante en el mundo de la burocracia y la política. Y el centro de ese mundo, al menos el trampolín para llegar a él, era obligadamente Madrid. Por Madrid había pasado el propio Mayans, y allí permanecería un grupo de valencianos íntimamente ligado a él y con los que Sempere establecería sólidos lazos. Por otra parte, el ilustrado alicantino nunca olvidó el peso enorme que Valencia tuvo en la Ilustración española, aunque públicamente lo callara, por motivos exclusivamente personales e ideológicos, como tendremos ocasión de ver. En aquel sentido se expresa Sempre en dos cartas dirigidas a la Sociedad Económica de Valencia. una de 1788 en la que, con

(39) Vid, Pascual Madoz: «Diccionario Geográfico-Estadísticop-Histórico de España y sus provincias de ultramar», Madrid, 1849, voz «Orihuela»

(40) «Ensayo», cit., los artículos dedicados a Mayans y a la Sociedad Económica de Valencia, IV, pág. 14 y V, pág.218, respect. 
motivo de recabar datos sobre la Sociedad para incluirlos en el «Ensayo», afirma su deseo de dar publicidad de ella, «tanto por ser una de las que han trabajado con más luces, como por mi natural inclinación a las cosas del pays en que he nacido» (41); otra, de 1802, desde la Chancillería de Grana$\mathrm{da}$, agradeciendo la recepción de las Actas de la Sociedad y anunciando el envío de tres de sus obras (Memoria sobre las causas de la ociosidad; Proyecto sobre Patronatos y Obras pías; Memoria sobre la renta de población del reino de Granada), donde se enorgullece una vez más de su condición: «Soy valenciano... Por consiguiente, no ha podido dexar de serme muy agradable la lectura de los loables esfuerzos de la Sociedad de mi pays para la pública felicidad» (42).

1780. Lo cierto es que, tras dos años escasos de «práctica de abogado» en la capital valenciana, nuestro buen Sempere decide ( $i$ de motu propio o aconsejado por alguien?) mandarse mudar a la bulliciosa y celebrada Villa y Corte del rey más ilustrado de la historia de España, donde la España eterna de «charanga y pandereta», la de los pliegos de cordel (43), se codeaba curiosa con las luminarias del clasicismo estético y la filosofía de las luces. Allí empieza a instalar, paciente y activamente, sus proyectos vitales el inquieto eldense que, de inmediato, dirige hacia tres frentes principales:

a) el mundo de la jurisprudencia, consiguiendo su puesto de abogado en los Reales Consejos y colaborando en la Academia de Derecho público de Sta. Bárbara; b) el ámbito socio-político, acercándose a la Sociedad Económica matritense, sobre todo, a partir del premio que ésta le concede, acompañado del nombramiento de socio de mérito; c) el ambiente literario-cultural, aparte las relaciones personales, traduciendo y publicando en 1782 las «Reflexiones sobre el buen gusto en las ciencias y en las artes», del prestigioso ilustrado italiano Muratori, añadiendo, además, de su propia cosecha, un apéndice sobre «el gusto actual de los españoles en la literatura» (44). Hay que resaltar que en esta época temprana, ya Sempere conocía bien el italiano y el francés, siendo partidario de que todo buen ilustrado pudiera leer la literatura importante en la versión original, dejando las traducciones para la gente menos preparada. Rasgo este importantísimo por lo que se refiere a su mentalidad plenamente ilustrada a sus veintiséis años, como por las posibilidades de acceso y recepción de la producción intelectuai extranjera. Puede afirmarse que nuestro ilustrado leyó mucho y bien a los autores que por entonces «había que leer». No parece probable que, dado su talante

(41) Real Sociedad Económica de Amigos del País de Valencia, 1785, C-15, VII, Varios n. ${ }^{\circ} 3$

(42) Ibídem, 1802, C-39, VII, Correspondencia $n .^{\circ} 2$

(43) Caro Baroja, Julio: «Ensayo sobre la literatura de Cordel», Madrid, 1969

(44) para otros datos, vid. «Noticias», cit, págs. 1 y 2; Carande, «Catálogo», cit. págs. 8 y 9; Rico y Montero op. cit., pág. 245 
pro-ilustración y su concienzuda laboriosidad, dejara escapar a su análisis algún autor considerado importante en el panorama de las luces. El mismo afirma que el buen ilustrado debe leerlo todo para aprender a discernir, es decir, a ser virtuoso en la aplicación a cada caso de aquello que la razón y el sentido común concierne al bien de la nación. Que en estos primeros años de Madrid no sólo había leído mucho, sino que había asimilado las principales ideas en boga, que iría después desarrollando en sus escritos, lo prueba contundentemente una ojeada a las disertaciones con que intervino en la Academia de Sta. Bárbara, de las que damos fecha y título.

febrero 1781: Las leyes suntuarias (es decir, siete años antes de publicar este tema en uno de sus más famosos libros)

febrero 1783:disertación técnica sobre las leyes del tit. 3, Partida 3 abril 1783:Los límites de la defensa nacional

mayo 1783:La facultad de imponer penas

enero 1784:La policía; en qué se diferencia de la política, quáles son los principales objetivos de una y otra; y se dará una idea de las mejores obras que se han escrito sobre ella.

mayo 1784:Sobre mayorazgo (veintiun años antes de su también famosa «H. ${ }^{a}$ de los Vínculos y Mayorazgos»)

octubre 1874:La policía de las diversiones populares; si éstas tienen influjo en el carácter de las naciones y quáles podrán fomentarse o deberán prohibirse. (premiada con una medalla de cuatro onzas de plata)

abril 1785:La necesidad y el plan de un código legal.

junio 1785:El antiguo Consejo del Rey. Origen, progresos y estado actual del de Castilla. División de sus salas con aplicación de los asuntos respectivos que pertenecen a cada sala, modo y forma con que substancia y determina los negocios.

marzo 1786:Los ramos que comprende la policía y modo de mejorar los pueblos en orden a la salud, construcción de edificios, limpieza de calles y entradas.

Como se puede yer, un amplio muestrario de las preocupaciones de nuestro ilustrado, que son las típicas de toda la ideología ilustrada y liberal europea, a las que los representantes españoles se aplicaron con un entusiasmo sólo minimizado por las deficiencias de la praxis política concreta y las trabas de los sectores reaccionarios. Aunque Sempere permanecio en Madrid hasta 1790, parece que abandonó sus disertaciones en la Academia bastante antes. Cierto es que ya entonces estaba enfrascado en la ardua tarea de recopilar y escribir su famoso «Ensayo», así como la «H. ${ }^{a}$ del lujo y de las leyes suntuarias de España» aquél aparecido entre 1785 y 1789 en la Imprenta Real en seis volúmenes y ésta en 1788 en la misma imprenta en dos volúmenes. 
Las motivaciones para escribir el «Ensayo», podríamos establecerlas en personales e ideológicas. Personales, en la medida en que una obra de tal envergadura, y con éxito asegurado en aquel momento, podría suponer un estupendo medio para el encumbramiento profesional y hasta político del autor. Ideológicas, porque, dados los precedentes en Inglaterra, Francia e Italia, principalmente, España necesitaba demostrar al mundo «civilizado» que en su seno estaban tan asentadas las «luces» y la Razón como en aquellos países. Por otro lado, hacía tiempo que en nuestro país voces autorizadas echaban de menos obras semejantes, como es el caso de Mayans, quien, según Mestre (45), ya en 1753, «planteaba implícitamente la necesidad de publicar las obras de los mejores humanistas hispanos». En esa línea cabe constatar la aparición, entre 1781 y 1786 , de la «Biblioteca Española» de Rodríguez de Castro, escrita con el intento de refundir y ampliar las famosas «Bibliothecas» de Nicolás Antonio. Pero es el propio Sempere quien plantea la concreta motivación, derivada de la aparición de un artículo en la Enciclopedia francesa, firmado por un tal Masson y que resultaba "sumamente injurioso a España» (46). Aunque tales injurias ya habían sido lavadas en parte - sigue refiriendo Sempere- en el mismo París por su paisano el botánico Cavanilles, aquél no se sintió satisfecho como patriota, por lo que decidió emprender la tarea de llenar un vacío informativo que no admitía más demora, habida cuenta

«la escasez de tales noticas que había aún en la misma España, por falta de buenos diarios y otros con que se propagan en otras partes» (47)

Sempere viene, pues, a suplantar una labor que él ya reconocía, con suma modernidad, como propia de la prensa, esto es, puramente didáctica e informativa.

La verdad es que no tuvo graves problemas para emprender la tarea. Antes bien, bibliotecas públicas y privadas, personalidades (su paisano el P. Andrés desde Italia, Jovellanos, Pérez Bayer, Blasco, Mayáns, Campomanes, Meléndez Valdés, Morajarava, Ulloa, Floridablanca, éste proporcionándole ayuda financiera para la impresión, etc.) instituciones como las Sociedades Económicas..., pusieron a su disposición todas las noticias que Sempere iba pidiendo. En este sentido se queja. F. Lópeż, quizá con razón, de la ligereza con que el alicantino se aprovecha de una obra en la que es más compilador que otra cosa. Oigamos a López:

«El método de Sempere es de los más simples: Pide a los autores que le suministren ellos mismos las reseñas que él llevará al conocimiento del público... cuando tal escritor ha cumplido la demanda, el complaciente compilador del «Ensayo», que a pesar de sus promesas contiene lo mejor como lo peor, reproduce, pura y simplemente, la no-

(45) Mestre, «Humanismo y crítica...», cit., pág.100

(46) «Noticias literarias», cit., pág. 3

(47) Ibídem, págs. 3 y 4 
ticia redactada por dicho escritor, el cual tiene por consiguiente toda libertad para otorgarse a sí mismo grandes alabanzas» (48).

El investigador francés lleva, como ocurre casi siempre, una razón relativa. En cualquier caso, las matizaciones autocríticas e intencionales de tal método las pone el propio Sempere tal como hemos apuntado más arriba y como puede también verse en el prólogo al primer volumen del «Ensayo». Incluso se le puede reprochar el que ni siquiera incluyera en su inventario a todos los ilustrados importantes, como hace notar M. Pelayo para el caso de Olavide. Sempiterno problema el de los criterios subjetivoideológicos de todo autor. Pero, ¿a qué obra no se le pueden encontrar omisiones y matizaciones subjetivo-ideológicas? ¿Y hasta qué punto son éstas conscientes o inconscientes? Por ejemplo, en la línea interpretativa de López, ¿hasta qué punto era consciente Sempere del grado de enojo que provocaría en Forner la inclusión en el «Ensayo» del artículo «Trigueros», en el que se satiriza al autor de la «Oración apologética», aún cuidando Sempere, como reconoce el propio López, de no hacer comentario alguno a favor ni en contra?

Después de todo, Sempere había incluido, en el correspondiente artículo (Ensayo, III, 84-89), la obra de Forner, sin dejar de hacer comentarios elogiosos de la misma como de su autor. De manera que el desliz cometido por Sempere lo vemos únicamente en el hecho de haber incluido, sin moderarlo ni retocarlo, el extenso y autoelogioso artículo de Trigueros. Lo que provoca que Foner contemple al autor del Ensayo como cómplice convicto del despreciado Trigueros, y arremeta contra la obra como

«un fárrago indigesto, destinado a levantar aras a muchos pigmeos que no eran conocidos sino de sí mismos, de un pequeño número de parciales; y a incensar con una goma pestífera a algunos ídolos que $O$ se reirían o despreciarían el interesado humo con que se le daba en las narices (49).

Como es fácil suponer, tras aquello, ambos ilustrados se ignoraron mutuamente durante algún tiempo hasta que, siendo Sempere fiscal en la Chancillería de Granada y ocupar Forner el mismo puesto en el Consejo de Castilla, tuvo aquél la gentileza de enviar a éste un ejemplar de su recién escrita «Observaciones sobre el orígen, establecimientos y preeminencias de las Chancillerías de Valladolid y Granada», envío al que acusa rápido y amistoso recibo Forner, para satisfacción de Sempere, quien salda la cuestión afirmando que «los verdaderos sabios olvidan fácilmente sus resentimientos personales» (50). Pero volvamos al debatido «Ensayo». En realidad, si nos detenemos en él es porque, al par de la importancia innegable

(48) López, F., op. cit., pág. 469

(49) Ibídem., pág.471 y nota 51

(50) Noticias literarias, op. cit., págs. 7 y 8 y nota 6 
como inventario ilustrado, pueden rastrearse también en sus páginas rápidas y sutiles opiniones, suficientes para perfilar las principales modulaciones ideológicas de nuetro taimado Sempere. Con ellas se trata de dar coherencia al retrato que apuntamos al principio, según el cual Sempere Guarinos sería, desde muy pronto y sin las rupturas ideológicas que algunos han aventurado, ilustrado y liberal, conservador y progresista y nunca reaccionario, a no ser, como dijo Machado de Azorín «por asco de la greña jacobina», pero de esta guisa también fue reaccionario hasta el cáustico Voltaire.

Empecemos con la idea de la decadencia española desde el s. XVII hasta la llegada a España de los Borbones. Sempere es uno de los contribuyentes a la extensión de la misma, como explica sobradamente en el prólogo al tomo I del «Ensayo». Asimismo, colabora en la radicación de la idea de que fue Feijoo el auténtico artífice de la introducción de las ideas ilustradas en España, junto a la gestión política de los Borbones (Ibídem). Sin embargo, el ilustrado conocía bien la producción intelectual española de esos años "decadentes», tanto en el terreno de la cultura como en el de la economía (Martí, Nicolás Antonio, Martínez de la Mata, etc.). Nos queda, pues, la sospecha de que tales afirmaciones sobre la decadencia tienen connotaciones puramente ideológicas: Se trataba, más que de vilipendiar el pasado, de potenciar las, para los ilustrados, enormes posibilidades que proporcionaba el presente para llevar a cabo la ansiada transformación sociopolítica y económica que precisaba el Estado español. Para ello, todo elogio a los nuevos gobernantes, que además se presentaban como defensores de las luces y el progreso, no era un mero arrebato literario o interesado, aunque también lo fuera.

Intimamente ligado a tal mentalidad está el que podemos llarmar «nacionalismo conservador» de Sempere. Así, no resulta fortuito el que reuniera los artículos del «Ensayo» por orden alfabético, sin mención de origen ni otros datos personales, ya que como él mismo nos dice (51)

«mientras una nación no llegue a consolidar en su seno el espíritu de unidad y de patriotismo, le faltan todavía muchos pasos que dar en la civilización. No es el mejor medio para extinguir la rivalidad de las Provincias el referir por menor las patrias de sus Escritores. Antes, acaso, convendría sepultarlas en el olvido, a lo menos por cierto tiempo, y que de ningún hombre de mérito de nuestra Nación se pudiera decir mas que es Español».

En tiempos de Sempere España se hallaba, según vemos, muy lejos de haber consolidado sus lazos como nación, por lo que su receta, paternalista, es la de un Estado fuerte y centralizado y un gobierno que con su hábil política redujera tales diferencias, "por el tiempo suficiente», hasta conseguir que cada español se sintiera adscrito a la unidad política superior que es el

(51) «Ensayo», cit., vol. II, pág. IX 
Estado moderno. Maquiavelo y Hobbes andaban, indudablemente, por la cabeza de nuestro ilustrado.

Otro rasgo del conservadurismo de Sempere lo da su actitud ante la nobleza, actitud, por otra parte, compartida por la mayoría de los ilustrados. No había que atacarla como clase social sino como clase ociosa e improductiva. Es decir, se sustentaban criterios económicos marcadamente liberales para enjuiciar, de una manera conservadora, una situación de facto. ¿Pensaba Sempere en privado como un Cabarrús o un Arroyal, explícitos en sus condenas adversas a la nobleza? Creemos que lleva razón Elorza al situar a Sempere como un convencido partidario de tal estamento como institución históricamente legítima:

«para Sempere la naturaleza de las cosas no puede violentarse, la constitución española no es el resultado de un proyecto filosófico, sino de un largo devenir histórico sobre el que sólo cabe operar mejoras parciales» (52).

He aquí, de nuevo, el progresismo reformista-conservador de un Burke, enemigo de todo cambio revolucionario. Pero no sólo está presente el pensador inglés, sino Montesquieu, a quien nuestro ilustrado conocía bien y de quien suscribiría las opiniones sobre la nobleza, según las cuales ésta sería lícita o legítima siempre que no olvidara de poner en práctica sus deberes políticos y sociales, aquéllos referidos a la función de contrapeso del absolutismo y éstos plasmados en la ejemplar colaboración en la ilustración de la sociedad. En otro lugar hace suyas Sempere las referencias que Cadalso, en una de sus tragedias desarrolla sobre las «obligaciones de la Grandeza» (53).

Por su parte, y es lo que nos interesa ahora, los rasgos «liberales» y plenamente modernos del ilustrado pueden rastrearse en diferentes vertientes:

a) Relaciones Iglesia-Estado. Las razones por las que Sempere era regalista, es decir, partidario de la supeditación política de la Iglesia al poder civil, eran propiamente políticas y también económicas. Políticas, porque el tema de la secularizàción del poder civil y de la separación Estado-Iglesia eran ya ampliamente aceptados por todos los ilustrados. Económicas, porque como dicen Mercader y Domínguez Ortiz,

«desde Macanaz a Sempere Guarinos, casi todos los economistas españoles del s. XVIII (Ustáriz, Campillo, Gándara, Campomanes, Floridablanca; Sisternes), coincidian en la necesidad de poner coto a los progresos de la acumulación de la propiedad territorial en manos de la Iglesia» (54).

(52) Elorza, op. cit., pág. 61

(53) «Ensayos», cit., pol. II, pág. 22.

(54) Mercader y Domínguez Ortiz: «H. ${ }^{a}$ de España y América», vol. IV, Barcelona, 1961, pág. 27. 
Es decir, que en la mente de estos hombres estaba clara la traba que suponía para el desarollo económico (y político) del Estado la vinculación de la propiedad a un estamento tradicionalmente poco propenso a la modernización. En la misma línea, Teófanes Egido (55) menciona a Sempere como a uno de los ilustrados que, junto a Campomanes, se hace eco («Ensayo», $t$. II, 77) de la enorme importancia de una política eclesiástica que sirviera a los intereses de una nación moderna y progresiva. En esa polémica ilustración-reacción se jugaba con mucho el futuro socio-político de España, de ahí que para los ilustrados fuera capital la urgencia de la modernizazión, una de cuyas secueias fue la expulsión de los jesuitas. Cabe citar, en torno a esta actitud moderna en materia religiosa, a Sempere como uno de los autores que no tuvieron reparos (a las represalias inquisitoriales) en hacer referencia en sus escritos al nombre de Erasmo, autores que, según López, fueron más numerosos de lo que creyera Domínguez Ortiz (56);

b) Educación - planes de estudio. Obviamente, el tema de la educación y la reforma de la enseñanza no iba a pasar de lago en las preocupaciones de nuestro ilustrado. No hay más que leer, en el «Ensayo», los capítulos dedicados a las universidades, a los planes de estudios o a la labor pedagógica de las Sociedades Económicas. En las famosas polémicas entre las universidades y el Consejo de Castilla sobre los Planes de Estudios, no sólo defiende la legalidad reformista, sino que aprovecha para despotricar contra el escolasticismo retrógrado reinante en aquellas, él, que lo había sufrido en sus propias carnes. Y aún va más allá de la mera reforma de los centros de enseñanza al exhortar al fomento de la lectura y el cultivo de las luces mediante las bibliotecas públicas y las ediciones baratas (57), lo cual no resulta una actitud meramente elitista;

c) Política social - minorías marginales. El problema de la regulación moderna de fenómenos como la pobreza y la caridad, los vagos, los presos, los gitanos y, en general, las minorías marginadas, lo toca Sempere en la «Memoria» premiada por la Soc. Económica, en el «Ensayo», desde su puesto de fiscal en Granada, en la «Biblioteca económico-política», etc. Su filosofía para remediar tales males, sociales y no naturales, se basaba en tres grandes líneas: instrucción (basada en la máxima general ilustrada: las causas de los males no son naturales sino políticas); política económico-legal (trabajo y jornal para todos); y control estatal e institucional de la caridad indiscriminada. La premisa de la que se paría era clara: el trabajo, entendido como esfuerzo humano tendente a la transformación de la naturaleza con fines útiles, era considerado como la más importante fuente de la ri-

(55) «H. de la Iglesia en España», vol. IV, cit., pág. 189.

(56) Lópes, op. cit., pág. 129 y ss. F. López atribuye a Sempere la defensa de Erasmo contenida en el «Discurso sobre el gusto de los españoles en literatura», de 1782 .

(57) Recogido también por N. Glendining, op. cit., pág. 43. 
queza de una nación, junto a la tierra (la consideración del capital como tercer factor básico, vendría pronto); por lo tanto, había que distinguir entre trabajo productivo y trabajo improductivo o inútil, con el fin de regular ambos y conseguir transformar la mayor parte de éste en trabajo productivo. Al pobre, al vago, al gitano, no había que considerarles, pues, como necesitados perennes, sino discernir entre sus capacidades laborantes y procurar integrarlos en la rueda de la producción nacional. Sempere, como tantos otros de su tiempo y en algunos casos más, estaba al tanto de las modernas teorías de los fisiócratas, de Hume y de Adam Smith, aunque atrapado por su formación excesivamente jurídica, no supiera ver todo el alcance revolucionario de la nueva ciencia económica;

d) Economía. En este campo el ilustrado eldense proporciona sugerencias quizá muchos más ricas que en otros. La clave de su ideología económica liberal-conservadora (en un estilo más inglés que español), la proporcionan tanto el «Ensayo», como la «H. ${ }^{\text {a }}$ del lujo», desarrollada después en la "H. ${ }^{a}$ de los vínculos y mayorazgos» y en la «Biblioteca económicopolítica», entre otras muchas menores. En el artículo del «Ensayo» sobre la Sociedad Económica de Valencia; por ejemplo, expresa agudamente la función del comercio como factor dinamizador y consuntivo de la producción, en un sentido claramente capitalista:

«Pero el pensamiento más útil en mi concepto, y más digno de adoptarse por las demás Sociedades del Reino, ès el de establecer una Compañía de Comercio, auxiliatoria de los proyectos de la Sociedad, cuyas reglas extendieron D. Joaquín Fos y D. Tomás Trabado en la representación del $n .^{\circ}$ 8. Sin una Compañía de Comercio, a cuyo cargo esté dar salida a los géneros y manufacturas fomentadas por las Sociedades, nunca saldrán éstas de meras tentativas y ensayos, arruinándose al instante, sin más utilidad que la pequeña gloria de haberse proyectado. Si se examinan las Actas de todas las Sociedades se verá que ha sido ésta una de las más principales causas porque no han prosperado mucho sus conatos y esfuerzos para fomentar la industria» (58).

Por su parte, Schumpeter (59), con su finura analítica, no duda en situar a Sempere junto a los pensadores «nuevos», que pueden parecer ambiguos cuando tratan temas como el lujo, pero que no lo son (y ahí radica su novedad) si descubrimos su verdadera intención: tratar el comportamiento (lujoso o suntuario, en este caso) únicamente desde la perspectiva de su rentabilidad económica para la nación, así como captar la intima correspondencia entré el progreso económico y el lujo. Aun cuando fuera una actitud que, en última instancia, necesitara de consideraciones morales y definitorias: qué es el lujo y quién puede sostener legítimamente un comportamiento lujoso. En fin, la consideración económico-moral del lujo que hace

(58) «Ensayo», cit., vol. V, págs. 226-227.

(59) Schumpeter, op. cit., págs. 376-377. 
Sempere es plenamente burguesa y, en su opinión, la falta de esa perspectiva por parte de los poderes tiene mucho que ver con las causas de la decadencia española, persuadido como estaba de que

«gran parte de ellas dimanan de sus errores económicos, y particularmente de las trabas puestas a los consumos de sus frutos y manufacturas con leyes suntuaris y otras mistificaciones" (60).

Para progresar, pues, hay que comenzar por la reforma fiscal.

La «H. ${ }^{2}$ del lujo» le valió a su autor renombre nacional y extranjero (nombrado individuo de la Academia de Florencia), y algo más inmediato: «su promoción a la fiscalía de Chancillería de Granada, sin consulta de la cámara y sin las bajezas a que se veían entonces forzados muy comúnmente los pretendientes de togas» (61).

e) Otra de sus actitudes «liberales» es la derivada de su aceptación de las tesis de Montesquieu, Beccaria y Betham en materia penal y civil, por las que se empezaba a considerar al preso como un individuo «recuperable» socialmente, convirtiendo las cárceles en centros de readaptación. El libro de Beccaria «De los delitos y de las penas», publicado en 1763, se había convertido en el vademécum de la jurisprudencia ilustrada y, según López, «su influencia es

«notable en numerosos ilustrados: Lardizábal, Azevedo, Sempere Guarinos, Jovellanos, Meléndez Valdés, Valentín de Foronda, etc.» (62).

f) Finalmente, el tratamiento que da Sempere a la historia como «maestra de la vida» (63), es un elemento más a destacar en su saldo de modernidad:

«...la historia siempre es útil... Persuadido yo también de la utilidad de la historia para la mayor ilustración dèl entendimiento, desde mis primeros estudios dediqué una parte de ellos a la general, y más particularmente al de las antigüedades españolas» (64).

Ramón Carande opina que

«sus argumentos históricos no son superfluos ni negativos: mas bien contemplan el pragmatismo de la vertiente romántica, en sus albores. Sempere busca la imagen del espíritu del pueblo en los acontecimientos. $\mathrm{Si}$, a diferencia de coetáneos suyos de la última época no es optimista ni liberal, como Jovellanos, acata las enseñanza de la historia y pretende desprenderse del lastre de "obstáculos» interpuestos que no están precisamente en la imaginación del autor, ni son lo sustantivo del devenir histírico» (65).

(60) «Noticias literarias, cit., págs. 5 y 6.

(61) Ibidem, pág. 6 y notas 3 y 4.

(62) López, op. cit., pág. 518.

(63) «H. ${ }^{a}$ del Derecho, cit., vol. II, prólogo.

(64) Ibidem.

(65) Carande, op. cit., pág. 22. 
Asimismo, según Dominguez Ortiz, hay que incluir a Sempere (con Cadalso, Forner, Cabarrús o León de Arroyal), entre la generación que trata

«la historia de España, tanto en su contenido formal como en la metodología crítica, de una manera enteramente nueva, pasando «de la crítica de hechos concretos a la de toda una época, a la de toda una dinastía) (66).

1790. El nombramiento (en febrero) para ocupar el ministerio fiscal en la Real Chancillería de Granada, reorientó la brillante carrera de Sempere en Madrid, no siempre para bien, dado su mayor compromiso con el poder y su nuevo status de alto burócrata. Además, como él mismo dice, le cortó el trabajo recopilador dedicado al «Ensayo». De todas formas, todo hace suponer que el nuevo destino fue bien acogido por el ilustrado.

\section{Refiriéndose a él, el flamante fiscal lo describe así:}

«La obligación principal de tal oficio es la de defender la jurisdicción real y los derechos de la Corona contra los abusos de las clases privilegiadas; y bien presto fuí teniendo nuevas pruehas de que no bastaba la instrucción legal adquirida comúnmente en las universidades y en el foro para desempeñarlo dignamente, sin el auxilio de la historia nacional» (67).

Acerca de la estructura orgánica de las dos Cancillerías existentes en la época, aparte el moderno trabajo de Molas Ribalta sobre la de Valladolid (68), es interesante espigar en las descripciones de observadores directos, como es el caso de Peyron y Townsend, viajeros curiosos de las cosas de España (69). J. F. Peyron, que pasó por nuestro país entre 1772 y 1773 , dice así:

«No hay más que dos cancillerías en España, a las cuales van a parar, por vía de apelación, todas las causas que se juzgan en el reino; y de éstas, en los casos previstos por la ley, pasan al Consejo de Castilla. La una es la de Valladolid, la otra está en Granada; está compuesta de dieciséis Oidores o jueces, que tienen voz con el presidente; de ocho Alcaldes, cuatro para lo criminal, cuatro para lo civil; de dos Fiscales o gentes del rey, y de un Alguacil mayor. Todos estos miembros en número de veintiséis componen lo que llaman la Chancillería... La justicia es alli administrada en seis salas, de ellas cuatro para lo civil, una para asuntos de la'nobleza y una para lo criminal» (70).

(66) Domínguez Ortiz: «Sociedad y Estado», op. cit., págs. 480-481.

(67) «H. ${ }^{a}$ del Derecho, cit., II, prólogo.

(68) Molas Ribalta, Pedro: «La Chancillería de Valladolid en el s. XVII. Apuntes sociológicos», en «H. ${ }^{\text {a }}$ social de la Admón. española», varios autores, Barcelona, 1980.

(69) En «Viajes de extranjeros por España y Portugal», Garcia Marcadal, recopilador, vol. III, siglo XVIII,Madrid, 1962.

(70) Ibidem, pág. 771. 
La descripción es correcta, aunque se ciñe únicamente a los llamados «ministros superiores», a los que hay que añadir unos trescientos funcionarios más o «ministros inferiores», que sí recoge Townsend (71). Pero sigue Peyron:

«...así es como llaman a los tribunales supremos de Granada y Valladolid. Se reparten todos los procesos de España en última instancia, porque las principales ciudades, como Barcelona, Valencia, Sevilla, etc., tienen tribunales de justicia, llamados Audiencias, cuyas sentencias..., están sometidas a apelación» (72).

Dos datos importantes podemos retener de tales palabras: a) por un lado, el papel de Sempere como agente especial del rey por su cargo, con las connotaciones ideológicas que ello representaba en orden a la actitud sobre determinados problemas y a la independencia de juicio. A lo que es preciso añadir que el jefe de la nación ya no era el ilustrado Carlos III sino su sucesor, Carlos IV, pronto víctima de las intrigas políticas que sembrarían el descontento entre numerosos ilustrados. Entre éstos, a pesar de todo, hay que situar al propio fiscal, quien recordando la situación años más tarde, la expresaría con las siguientes amargas palabras:

«Todavía fueron mayores y más permanentes aquellos adelantamientos - se refiere a la política de los primeros borbones-, si acabaran de llevarse a afecto las reformas proyectadas. Mas no habiéndose arrancado de raíz las principales causas de nuestros errores y preocupaciones, volvieron a producir los mismos males en el reinado de Carlos IV.

«Aquel desgraciado rey se dejó persuadir que un joven -se refiere a Godoy - sin más principios ni práctica que la de montar a caballo, sería muy a propósito para gobernar esta vasta y complicada monarquia.

«... (sigue refiriéndose a la impericia de Godoy y sus amigos.)

«Tales eran los oráculos de la Corte y del Consejo en los primeros años del reinado de Carlos IV. En un estado libre (subrayado nuestro) la impericia de un privado no es bastante para arruinarlo si no se agregan otras causas. Mas en un gobierno monárquico un solo ministro inepto puede destruir en pocos años las instituciones más utiles de muchos siglos" (73).

¿Fue Sempere un incondicional del despotismo, un servil, como se le imputa? Luego de tales afirmaciones, que indican un sentido de la historia y la teoría políticas muy moderno, hay, por lo menos, que matizarlo.

b) Por otro lado, de las palabras de Peyron se desprende un hecho, o más bien un problema, derivado de la ausencia en la España ilustrada de una di-

(71) Ibídem, pág. 1.586 .

(72) Ibídem, pág. 915.

(73) $\left\langle\mathbf{H},{ }^{a}\right.$ del Derecho», cit., II, pág. 386 SS. 
visión de poderes en sentido moderno, tal como la proclamaba el pensamiento constitucional europeo, con Locke y Montesquieu al frente. De ahí que determinados asuntos generaran, por ejemplo, el problema de la jurisdiccionalidad entre las Cancillerías y las Audiencias, cuestiones que Sempere intentaba resolver con el «auxilio de la historia nacional». En la medida en que las Cancillerías habían sido creadas para defender la jurisdicción real y los derechos de la Corona, resultaba lógico que se les atribuyera mayor competencia ejecutiva y judicial que a las Audiencias, máxime por sus propios funcionarios. Es el caso de Sempere ante una controversia entre la Cancillería granadina y la Audiencia de Valencia, que hizo intervenir al propio Consejo. Sempere aportó sus ideas al respecto, como agente de la corona y partidario del despotismo legal ilustrado que era, escribiendo en 1796 sus importantes «Observaciones sobre el origen, establecimiento y preeminencias de las Chancillerías de Valladolid y Granada».

Sobre los veintidós años pasados por el ilustrado en Granada como fiscal y como ciudadano poco podemos añadir aún a lo ya publicado. Una reciente y rapidísima prospección en los fondos de la Cancillería, de la $\mathrm{Bi}$ blioteca Universitaria (en el hermosísimo edificio restaurado del Hospital Real), de las bibliotecas de Letras y Derecho, en Granada, no ha sido muy fructífera, como no sea para constatar el hecho de ciertas desapariciones «extrañas» de papeles de y sobre Sempere.

Sin embargo, algo encontramos. Molina Fajardo (74) recoge, en su historia del periodismo granadino, un dato sobre la gestión de Sempere como fiscal de la Chancillería, que, entre sus atribuciones, también poseía las de policia:

«Como prueba de las trabas que se le ponían a los editores, señalamos el caso de un Diario de Granada no publicado. El año 1792 se pidió autorización oficial al presidente de la Chancillería, don Francisco Morales y Sotomayor, para editar un periódico. Se le exigió (al editor) que presentase un ejemplar manuscrito para ser examinado, y entregó uno en cuya cabeza contaba «Diario de Granada» del sábado 9 de junio de 1792. Fue remitido al fiscal de Su Majestad, don Juan Sempere Guarinos, quien informó desfavorablemente, por lo que el Real ACuerdo denegó la petición en 14 de junio de 1792. Cuatro años más tarde pudo ser vencida la resistencia de los miembros de la corte granadina, surgiendo entonces la publicación más interesante del s. XVIII (en Granada), y con la que nace la organización del periodismo con ajustada visión europea».

¿Fue el físcal en esta gestión un simple portavoz de la prohibición, o tuvo responsabilidad directa en ella? La segunda posibilidad significaría una fuerte incoherencia con las ideas anteriormente sostenidas por él en re-

(74) Molina Fajardo, Eduardo: «H. ${ }^{a}$ de los periódicos granadinos (ss. XVIH y XIX). Granada, 1979, pág. 58. 
lación al papel ilustrado y reformador de la prensa, que ni siquiera con. cuerda bien con el poder que, en teoría, le daba su status burocrático. En fin, esperamos en lo sucesivo dar más luz a estas cuestiones, por el momento conjeturales. No obstante, aportamos otro dato que puede significar un cierto contrapeso a la postura anterior. Se trata del periódico «Mensajero Económico y Erudito», que en su primer número ( 2 de junio 1796) cita «una Chancillería compuesta de doctos Magistrados que saben conservar el gusto por las Humanidades en medio de las ocupaciones del Foro» (75).

¿Desea el periódico únicamente congratularse con la máxima autoridad policial o, además, hace un elogio soterrado a algún miembro ilustrado del tribunal? En cualquier caso, hay que tener siempre en cuenta que por aquel entonces Granada era, a los ojos del poder establecido, un lugar que merecía especial vigilancia y protección por su pasado «peligroso» y herético (árabes y judíos). Por ejemp., Townsend cuenta que aún «en 1726 la Inquisición hizo detener a 360

«familias acusadas de estar secretamente unidas a la religión mahometana. Es probable que la acusación fuese cierta, porque el tribunal de la Inquisición, en medio de todas sus imperfecciones es notable en los cuidados que pone en la investigación de los hechos»' (76).

Quizá estas circunstancia poco propicias a las libertades, más el interés por conservar el puesto, influyeran en el hecho de que en la larga etapa granadina, Sempere dedicara su aplicación fundamentalmente a asuntos legales concernientes a su condición profesional y que, incluso los escritos más polémicos y «políticos», los tratara desde una óptica básicamente legalista. Es el caso de la «Memoria reservada al Príncipe de la Paz sobre la educación del Reino», de 1797; de los «Apuntamientos para la historia de la Jurisprudencia española», de 1804; de la «H. ${ }^{a}$ de los Vínculos y Mayorazgos», de 1805; de la «Memoria sobre las causas de la decadencia de la seda en el reino de Granada», de 1806; en fin, de las «Observaciones sobre las Cortes y sobre las leyes fundamentales de España», de 1810. Además, en Granada trabajó en la «Biblioteca económico-política», cuyo primer volumen apareció en 1801 y luego fue demorándose hasta 1821. Pero de toda la producción granadina, tal vez la más importante sea la $" \mathbf{H} .^{\mathrm{a}}$ de los vínculos y mayorazgos», considerada por muchos como el más importante precedente teórico de la posterior política desamortizadora liberal. De ello da medida el que fuera reeditada en 1847 en la «Biblioteca de Jurisprudencia y Legislación». Esta obra la escribió Sempere como respuesta al Expediente sobre la Ley Agraria promovido por el gobierno, aunque el texto escogido como oficial fuera el de Jovellanos. Sempere, pues, no había olvidado sus

(75) Consultado en la Biblioteca Universitaria de Granada, donde se conserva. Hemos perdido la referencia.

(76) «Viajes de extranjeros», cit., pág. 1.587. 
deberes de ciudadano ilustrado-reformador, ni relegado sus contactos con Madrid, cuya Academia de la Historia le nombra correspondiente en 1803.

En Granada le sorprendió el vendaval de la ocupación francesa y de la guerra de la independencia. Allí, entre el patriotismo y el desencanto, formó parte de la Junta de Defensa, cuya Memoria redactó a instancias de la Central; y allí, forzado por la «retórica de quince mil bayonetas» (77), juró al gobierno invasor, si creemos en sus propias palabras,

«no por perfidia ni odio a su rey legítimo, sino por la firme persuasión de que habiendo renunciado a la corona Fernando VII, era el único medio de salvar su patria y de curar las profundas llagas con que le tenían postrada la impericia y la perversidad de los gobiernos anteriores.

«Así pensaba Sempere, y a consecuencia de su opinión juró a José y continuó en su oficio fiscal, aunque de mala gana pero de buena fe. No se disculpará alegando que hizo su juramento con restricciones mentales, con segundas intenciones y con ánimo deliberado de aparentar obediencia a aquel gobierno para venderlo clandestinamente. Tal jusuitismo nunca convendrá con sus princios" (78).

Sorprende en tales declaraciones la entereza de principios y el peculiar sentido del honor de este hombre para eliminar cualquier acusación de oportunismo (él, que iba a recibir tantas), actitud sólo comprensible por su optimismo progresista, que le llevaba a creer que ni siquiera aquellas posturas aparentemente antipatriotas ni aquellos acontecimientos críticos $\mathrm{y}$, según él,coyunturales, iban a frenar el proceso transformador «positivo» de las estructuras sociopolíticas de España. Si no entendemos esa ideología pregresista y conservadora a un tiempo, difícilmente calaremos en la mentalidad de nuestro ilustrado.

1812. Parece que en junio de este año es Sempere promovido por el gobierno bonapartista al Tribunal Supremo de Justidia de Madrid, donde desempeña correctamente, según su costumbre, las funciones «técnicas» que le corresponden. Ninguna alusión a otras actividades. En la primera expulsión de los franceses de la capital, es encarcelado junto a otros afrancesados hasta la vuelta de aquéllos, en que es puesto en libertad, coyuntura que aprovecha para refugiarse en Elda con su familia. Allí permanece, como se ha visto ya, mientras los franceses son expulsados difinitivamente del pais, y hasta la restauración absolutista fernandina de 1814 , es decir, unos pocos meses, conservando la vieja esperanza progresista de re-iniciación del proceso ilustrado que ahora debía ser, además, constitucional.

1814-1820. Primer exilio. Parece ser que el exilio, en sus dos etapas, fue para Sempere; dentro de la ineludible nostalgia, bastante llevadero. Tu-

(1/) «Noticias literarias», cit., pág. 14.

(78) Ibídem. págs. 14-15. 
vo medios, materiales y afectivos, para instalarse cómodamente, y como él dice, «poderme entregar todo a los estudios más análogos a mis ideas y sazonar algo más mis conocimientos» (79). Állí escribió la polémica «Histoire des Cortes d'Espagne», publicada en Burdeos en 1815, unos años después de la «Teoría de las Cortes» de Mrtínez Marina. Aquélla, que matizaba las tesis de ésta fue malinterpretada tanto por los liberales como por los reaccionarios, aunque algo fundadamente por parte de los primeros, cuyas ideas estaban ya más cerca del republicanismo que del monarquismo. Es digna de destacar, en ese contexto, por lo que ilustra la posición más íntima de Sempere, su enérgica protesta contra el sector reaccionario europeo, que empleó indigna y parcialmente para sus fines la obra en cuestión. Así lo expresan las cartas que envía al editor de la Gazette de France con el fin de puntualizar su postura a tal manipulación (80).

1821-23. Regreso a España. Aparte lo ya reseñado, cabe destacar la voluntad de colaboración y congratulación de Sempere con el gobierno constitucional, al presentar a las Cortes dos obras especializadas, bien acogidas, al parecer, por la Cámara: Las Memorias para la historia de las Constituciones españolas. Memoria primera sobre la constitución gótica española», y otra sin firmar, cuyo título reza así: «Los principios de la Constitución española, o sea, concordia entre los derechos del Estado y los de los antiguos vasallos y señores. Por un jurisconsulto españo»; la primera escrita en el exilio y ésta casi sobre la marcha a su regreso (publicada por Repullés en 1821).

Sempere tenía doble motivo en esta ocasión para ponerse al servicio del constitucionalismo, aparte de su propio interés: La sanción y suscripción que el rey había hecho de la Constitución, vieja premisa del ilustrado. ¿Innaginaba el sesudo ciudadano que Fernando estaba esperando su oportunidad para volver al absolutismo y a la persecución de «enemigos de la Patria?» Como quiera que fuese, aquélla llegó y Sempere tuvo que optar de nuevo por el amargo exilio.

Pero, antes había dado muestras una vez más de su laboriosidad terminando su Biblioteca económico-política y publicando varias obras: las «Noticias literarias», citadas, la «H. ${ }^{a}$ de las rentas eclesiásticas de España» (1822), viejo caballo de batalla del ilustrado, y la «H. ${ }^{a}$ del Derecho español» (1822-23, 2 vols.), que supone un esfuerzo compilador y continuador, desde el punto de vista de la legalidad histórica, de sus anteriores historias constitucionales, «para que comparada con ellas la actual resaltaran más su racionalidad y sus ventajas sobre las antiguas» (81). Esta obra tuvo suce-

(79) «H. a del Derecho», cit., II, prólogo.

(80) Contenidas en las «Memorias para la h. ${ }^{2}$ de las constituciones españolas», Farís, 1820, pág. 191-194.

(81) «H." del Derecho», cit., I, prólogo. 
sivas reediciones y ampliaciones en 1884, 1846, y 1847 (dos) (82), y nos consta que ha sido ampliamente tenida en cuenta hasta hoy en las Facultades de Derecho de la Universidad española.

1823-26. Poquísimas son las noticias del segundo y último exilio que no sea la producción de las «Considerations sur les causes de la grandeur et de la decadence de la Monarchie espagnole», publicada en París en 1826 y traducida al alemán tres años después. Erá obvio que el tema del proceso histórico-político español obsesionara a un hombre que había dedicado sus mayores y mejores energías al servicio del progreso de su país.

1826-30. Ultima etapa vital. A fines de 1826 llega Sempere a Madrid procedente de Paris, donde había pasado los últimos años. En Madrid permanece hasta mayo de 1827 , ocupado en diversas gestiones, entre ellas la de otorgar testamento de sus bienes, hasta que se trasladó definitivamente a su pueblo natal, donde, según su paisano Lamberto Amat, fue recibido multitudinariamente por parientes, amigos, autoridades y curiosos en general, «con las mayores muestras de alegría y respetuoso cariño» (83), dedicando sus ajetreadas energías en lo que siempre las ocupó: produciendo ideas para el fomento de la mayor felicidad de la nación. Estos manuscritos, para los que empleó a varios escribientes, pasaron al patrimonio de sus herederos, y cuál será su paradero actual es un emigma que ojalá podamos desentrañar.

El 18 de octubre de 1830 , a los setenta y seis años de edad, moría en su pueblo y de muerte natural, un hombre tildado de incoherente pero extrañamente fiel a unos principios cuya aplicación práctica en un país como España, tan poco europeo en muchos aspectos de su historia, resultaba poco menos que milagrosa. Ahí está nuestra historia.

Para entender el pensamiento de españoles como Sempere (que los ha habido siempre y que los hay, con gradaciones del optimismo al pesimismo antropolígico-político), hay que irse a otras fuentes, a Francia, pero sobre todo a Inglaterra y Estados Unidos (84), donde el maniqueísmo reacciónrevolución, por ejemplo, lo entienden con matiz diverso que aquí. Pero oigamos, para terminar, al propio Sempere:

«La revolución de Francia ha sido efecto, no tanto de la filosofía a que se atribuye comúnmente, como de los errores y caprichos de su Corte. La nuestra estaba llena de vicios muy semejantes a los que habían producido alli tan memorable crisis. Los aduladores, ignorantes y

(82) Palau Dulcet: «Manual del libro hispanoamericano», Barcelona, 1948, vid. «Sempere Guarinos».

(83) Rico y Montero, op. cit., pág. 248.

(84) Sobre el particular, vid. el buenísimo estudio de Díez del Corral «El liberalismo doctrinario», Madrid. 
fanáticos, interesados en el desorden, temieron su propagación en esta península y pensaron atajarla impidiendo los progresos de las luces». (85).

(85) «H. ${ }^{a}$ del Derecho», cit. II, pág. 388. 


\section{ANEXO \\ CERTIFICACION ACADEMICA DE LOS ESTUDIOS REALIZADOS EN ORIHUELA POR JUAN SEMPERE}

«D. Salvador Puche, Rector y Presidente de los Seminarios de S. Miguel y la Purísima Concepción de Orihuela, certifico: que D. Juan Sempere y Guarinos tiene hechos en él los Exercicios literarios siguientes:

«Fue admitido a los diez años de su edad en dicho Seminario de la Purísima Concepción, por Colegial Porcionista, para continuar la Gramática que fuera de él había empezado, la que concluyó en su primer año de Colegio; empleando el segundo en repasar ésta, estudiar la Prosodia, Mtro, etc., y algunos principios de Retórica, de todo lo cual fue examinado al fin de cada año con universal aprobación de todos los maestros.

"Concluida la Gramática y Hümanidades, dio principio a la Filosofía, la que cursó por tres años, y en éstos defendió las Conclusiones, Sabatinas, Mensales y Generales que por Constitución le tocaban, y al fin de cada año Tentativas también Generales sin ayuda de Presidente, arguyendo al mismo tiempo a sus condiscípulos en los respectivos actos, que le correspondieron según el Estatuto de su Colegio; y siendo examinado al fin de cada Curso por todos los Maestros, consiguió siempre una muy noble censura, y en el último la mayor y el premio señalado por el Ilmo. Sr. Don José Tormo, actual Obispo de esta Ciudad.

"Concluido el curso de dicha Facultad, fue probado por todos los Maestros del Colegio-Seminario con un muy rígido examen de todo él, fuera del particular del año, los que le declararon apto para defender un acto General de toda la Filosofía Peripatética, según la mente del Angélico Doctor Sto. Tomás, ilustrada con varios principios y tratados de Física moderna, y algunas proposiciones Matemáticas del P. Tosca, lo que executó con universal aplauso en el Templo de Sta. Justa de esta Ciudad, habiendo precedido otro de prueba en su Colegio. 
«Pasó a la Theología, cuyo curso acabó en cuatro años cornpletos, defendiendo en ellos las Sabatinas, Mensales, Generales, Tentativas, y leyendo todos los años de Oposición, ya con término de cuarenta y ocho, ya con el de veinticuatro horas, y haciendo los demás exercicios según el riguroso método de este Colegio.

«Estudió después un año de Escritura, y en el mismo leyó también de Oposición en el término de veinticuatro horas y satisfizo a cinco argumentos que le objetaron tres Colegiales y dos Cathedráticos.

"Acabada la Theología recibió el grado menor y mayor en la Universidad de esta Ciudad, depués de haber precedido con los requisitos mandados por Su Majestad y sacado la aprobación completa de todos los Vocales.

«Estando cursando el segundo año de Theología, y a los dieciseis de su edad, fue admitido al concurso de oposición a una Cathedra de Filosofía vacante en esta Universidad y mereció el segundo lugar en la censura y terna remitida a Su Majestad.

«Fue destinado por el Ilmo. Sr. Don José Tormo para vestir la Beca que pertenece a su elección en el Real Seminario de Theólogos de San Isidoro de la Ciudad de Murcia, y la obtuvo dos años, distinguiéndose y creditando en su buena conducta y en el estudio de Escritura, Concilios, Historia Eclesiástica, Oratoria Sagrada, Moral, Mística y Ritos Eclesiásticos, según consta por certificación auténtica de aquel Seminario.

«El Mismo Sr. Ilmo. le confirió el título de Cathedrático de este Seminario, la que está exerciendo con exactitud y en cuyo cumplimiento ha presidido los actos que hasta ahora le han tocado, que han sido quince, y corroborado argumentos en otros muchos.

"Todo lo cual consta de los Libros de este Colegio a que me remito y para que conste lo firmo en este Seminario de Orihuela a 24 de abril de 1777.

«Don Salvador Puche». 